\title{
Correspondence
}

\section{Relationships with patients}

Sir: As Dr Harry Kennedy's article (Psychiatric Bulletin. April 1999, 23 193-194) makes clear, the current statutory provision for the supervision and treatment of patients in the community is in need of reform. Many of the remedies which Dr Kennedy asks us to consider seem sensible enough. I am sure he has earned himself a respectable place in that steadily accumulating genre: Mental Health Act; sub-category 'What is to be done?'. Yet am I alone in thinking that much of this copy misses the point.

Dr Kennedy talks about psychiatrists being caught in a "gap between freedom and responsibility", but perhaps the real gap lies elsewhere and has more to do with the discrepancy between the Hippocratic clinical ideal and the practice of psychiatry today - in the community and elsewhere. Historically speaking, more than most medical specialities, psychiatry has shown itself willing to court the state rather than the patient, to replace care with control, and to prefer obedience over gratitude. Of course the public knows this and is understandably suspicious. Naturally, a public which fears psychiatry will fear mental illness that much more, and, paradoxically, demand more fearsome powers for psychiatrists; hence the escalating public anxiety, and hence the tremendous public relief. excitement and blame when someone else always someone else - goes publicly and dangerously 'mad'.

At a time when the College is seeking to change minds and campaign against stigma, surely, we would be engaging in a much wider debate about the nature, conditions and consequences of the kind of social relationship we as a profession can and do establish with our patients.

JOHN LOWE, Specialist Registrar, Department of Psychological Medicine, University College Hospital, Grafton Way, London WC1E 6AU

\section{The value of advocacy: putting ethics in to practice}

Sir: I can not agree more with Thomas \& Bracken (Psychiatric Bulletin, June 1999, 23, 327-329) on the need to strongly support advocacy for individuals with mental health problems. It is however untrue that representation of patient's interest will 'inevitably' cause conflicts with psychiatrists.
On the contrary, the advocacy services need to be more transparent in order to improve their image and reputation with the treatment team. 'Transparent advocacy', should entail an open. logical and justifiable representation of patients wishes, needs and interests in order to promote their autonomy and welfare. It should not just be a pseudo-political stance of 'protecting patients' rights'.

Drawing particular instance from advocacy in learning disability services, I often do not understand how advocate workers reach their conclusion about what is in the best interest of the patients. In my opinion, they should share and explain the basis of decisions made on patients behalf, with multi-disciplinary team members. Otherwise they will continue to portray themselves as fundamental sentimentalists, opportunists or, indeed, anti-psychiatrists. Unless and until advocacy is seen to be transparent and reasonably substantiated, it will be viewed by some, with scepticism.

OLADIMEJI KAREEM, Senior House Officer in Learning Disability Psychiatry, Oxford Deanery Rotational Training Scheme, Northampton Healthcare Trust, Postgraduate Centre, Princess Marina Hospital, Upton, Northampton NN5 6UH

Sir: In their review, Thomas \& Bracken (Psychiatric Bulletin, June, 1999, 23, 327-329) point out the potential benefits of advocacy in psychiatry and the importance of junior doctors being exposed to advocates during their training. As a junior doctor in training. I have been exposed to advocates, with a mixed experience of their usefulness for patients.

On ward rounds, patients sometimes ask advocates to attend in order to help to express their views and ask questions about treatment. I have witnessed conflicts with consultants over whether advocates should be permitted to attend. Advocates have the advantage that they can concentrate on particular patients, while the doctor sees all the patients as well as performing other duties. At times I have found the information which I have given to be in conflict with that given by the advocates. In one case, a patient with mania which had proved resistant to treatment with conventional agents was being treated with gabapentin, an anticonvulsant for which there is evidence in open studies for 